\title{
Risk Management Mitigation in the New Normal Era
}

\author{
Oscarius Yudhi Ari Wijaya \\ Management Study Program of Academy Secretary and Management Indonesia (ASMI) Surabaya, Indonesia \\ artaprima@gmail.com
}

\begin{abstract}
The mitigation of business risk management in the Covid 19 pandemic is a powerful means of controlling the transmission and easing of socio-economic interactions. To avoid Covid 19 transmission, business organizations should adopt new cultural behaviors that align with proper health protocols to avoid Covid 19 transmission. This is because there are differences in the behaviors of business organizations. This research uses a qualitative approach with a literature study. It focuses on business and management mitigation risk factors in Covid 19 pandemic, as well as their impact on its transmission. The results show that the Covid 19 pandemic risk impacts private businesses as well as the state as a public organization entity equally responsible for solving the problem. Furthermore, no business is ready with adequate risk management planning for Covid 19 transmission. This has an impact on the risk of uncertainty for business sustainability. Moreover, there needs to be a proper theoretical, conceptual, and empirical risk management mitigation of Covid 19 transmission. Consequently, this enhances the control of transmission in office and business place clusters.
\end{abstract}

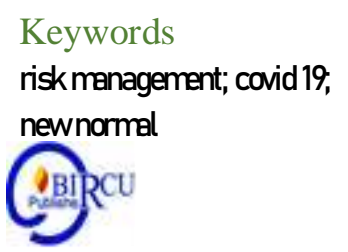

risk management; covid 19; newnormal

\section{Introduction}

The prolonged Covid19 pandemic has contributed to economic and climatic uncertainty in business. This is because the development of Covid19 transmission greatly determines government policy implementation in social restrictions. Moreover, it influences the general public's socio-economic behavior, causing fluctuations in business risk development. The idea of a New Normal emphasizes the importance of handling health problems while minimizing economic risks. By sustaining the economy during a pandemic and implementing strict health protocols, the new normal is the most rational approach and policy in response to the concerns of business sectors. This includes the micro businesses that have fluctuated due to economic difficulties during strict social restriction policies.

The problem is applying gas and brake policy with stricter social restrictions when the Covid19 pandemic increases. Consequently, it narrows down the business movement to become more complicated and limited, increasing the risk. This means that morals, ethics, and legality must be internalized into business interests. As a result, business actors become more obligated to build a new habitual tradition that ensures minimal transmission of Covid 19 when social interactions are loosened. This is another effort to build a business risk management mitigation. Efforts to mitigate business risk management in the Covid 19 pandemic are a powerful means to control the transmission and ease socio-economic interactions. To avoid Covid 19 transmission, business organizations should adopt new cultural behaviors that align with proper health protocols to avoid Covid 19 transmission. This is because there are differences in the behaviors of business organizations. 
The Covid 19 transmission significantly increased in the office sector shortly after implementing the new normal era and reopening several businesses. Moreover, restaurants are globally recognized as a means of transmitting Covid 19, contributing significantly to increased positive confirmed cases. This confirms the unique interactive behavior between people in business organizations.

Building a new habitual culture in business organizations naturally faces the challenge of natural human indecisiveness towards change. This regards the behavior that overly ignores the dangers of Covid 19 transmission at work when interacting with other people. There are several reasons for this, including social discomfort or fear of being in contact with objects that potentially transmit Covid 19, especially those used for public or shared interests.

Resistance to such change is understandable during a global pandemic and the resulting stress. Therefore, persuading others to build new strict habits in business organizations is an essential and decisive key to success. This means that it is necessary to creatively translate the vision of change into actionable and measurable behavior.

According to Jerome Payne (2020: 2), this situation is relevant to the behavioral approach summarized by Kotter's Model. It involves 3 stages, including planning, enabling, and embedding.

Business risk management mitigation in the Covid 19 pandemic requires companies to create new climate change habits acceptable and in line with all organizational levels and culture. Hence, when the necessary changes are initiated, all business organization members accept and regularly implement them with order, responsibility, and discipline.

When business risk management mitigation is planned correctly, new behavioral changes should be communicated. Also, actions to implement the behavioral changes should be initiated (enabling). The next step is the momentum where changes producing a new culture are integrated into business organizations' habits and structures (embedding). This paper builds an excellent overview of developing a business risk management mitigation strategy by organizations in the Covid 19 pandemic. The strategy should contribute to controlling the Covid 19 transmission when businesses resume with the enforcement of new habits. This is achieved by first planning sound business risk management mitigation (planning). The second step is socializing good risk management (enabling). The last step is internalizing risk management into an adequate and promising corporate culture and habits (embedding).

\section{Review of Literatures}

Erokhin and Tianming Gao (2020) examined the impact of COVID-19 on Trade and Economic Aspects of Food Security: Evidence from 45 Developing Countries. The study revealed the interactions between people's food security status and the dynamics of the COVID-19 case, trade, inflation, and currency volatility.

The results show that the COVID-19 insecurity effects are more pronounced in upper-middle-income than in developing countries. The food security risk is associated with a health crisis concerning economic access to adequate food supply. The risk of food availability security due to trade restrictions and currency depreciation is more common in high-income developing countries.

Mary Loxton, Robert Truskett, Brigitte Scarf, Laura Sindone, George Baldry, and Yinong Zhao (2020) examined Consumer Behavior in Crisis: A Preliminary Study of How the Coronavirus Has Caused Consumer Purchase Panic, Group Mentality, Changes in Discretionary Expenditure and the Role of Media in Influencing Behavior. 
The study analyzed panic buying, group mentality, and changing consumer discretionary spending patterns (according to Maslow's theory). This analysis was based on consumer spending data, mostly focusing on the Australian and American markets. The other aspects that were analyzed include the volume and time of consumers' spending patterns, as well as the expenditures on the goods with great demand during the study. Moreover, the expenses for luxury and non-durable goods were analyzed to identify this consumer behavior.

The results show that, amid the COVID-19 crisis, consumers behave in the same way as during historic shock events. Such historical crises and shock events included the SARS outbreak in 2002-04, the Christchurch earthquake in 2011, and Hurricane Irma in 2017. Similarly, COVID-19 significantly influences the changes in consumer behavior, affecting global economic conditions. Consequently, this results in significant economic downturns, company, and industry failures, as well as increased unemployment.

May McMaster, Charlie Nettleton, Christeen Tom, Holland $\mathrm{Xu}$, Cheng Cao, and Ping Qiao (2020) examined Risk Management: Rethinking Fashion Supply Chain Management for Multinational Companies as the Impact of COVID-19 Outbreak. The study examined the current fashion supply chain, recent and historical risks, as well as the mitigation methods used.

The results found that the optimal Supply Chain Management (SCM) structure largely depends on specific company characteristics. Lean SCM is preferred because of its cost advantages and reduced waste. This structure is constrained by a lack of supply chain transparency, causing the increased demand volatility even before the COVID-19 outbreak.

The fashion industry demand has been disrupted by widespread lockdowns and an economic downturn, resulting in lower consumption. There is a need for further research and guidance on building agility to reduce the SCM risks caused by the Covid 19 epidemic.

Companies should implement risk management strategies to incorporate greater agility into the supply chain (SC). They should consider source dependencies and introduce buffers to reduce the impact of disruptions. Furthermore, companies should help their top suppliers deal with bankruptcy and ensure adherence to social distancing restrictions to protect the long-term interest. A storage strategy based on actual rather than forecasted demand produces greater flexibility for some companies. Additionally, companies need to invest in online customer experiences to control demand disruption and maximize sales.

\subsection{Risk Management and Uncertainty}

There is an agreement that risk is related to uncertainty. This means that there is a risk due to uncertainty. Furthermore, risk is a possible loss because it happens to a company that fails to carry out good management. Therefore, the risk emerges because the company fails to apply sound management (Kertonegoro, 1996).

Risk management is generally the implementation of management functions in dealing with company risks. This includes planning, organizing, compiling, coordinating, and supervising risk management programs. Kerzner (2004) stated that the definition of risk management is diverse. However, it basically concerns the methods used by a company to prevent or overcome a risk.

Risk management is an application of general management that deals with various activities that may pose risks. According to Siagian and Sekarsari (2001), risk management focuses on purchasing insurance and managing the organization's overall risk. 
Risk management is a number of directed and proactive activities or processes to accommodate possible failure in one or a part of a transaction or instrument. Therefore, it is a dynamic process in line with changing business needs and risks. According to Abbas Salim, risk is an uncertainty that may result in losses (Kasidi, 2010).

\subsection{Risk Management Mitigation}

Risk mitigation is taking steps to reduce losses due to the impact of risks. Since the risk is unknown, proper management is necessary to avoid disrupting the continuity of main business processes. The significant problem in implementing a risk management method is continually identifying the costs. However, the costs are smaller than the actual risk (Siagian and Sekarsari, 2001). Risk management mitigation consists of identifying and evaluating each risk, as well as selecting and implementing a method and the control stage (Dorfman, 2000). The implementation to apply a method affects direct and indirect costs.

\subsection{Steps of Business Management Risk Mitigation}

Business risk management is structured to protect a business from a probable risk hazard, including employees, property, and reputation. Preventive measures must deal with the identified risks because it is impossible to eliminate or avoid all of them. According to Jasmin Harvey (2005), the risk management mitigation steps include identifying, assessing, responding, implementing, evaluating, and reviewing.

These steps are intended to identify possible risks (identification) in an organization or company. This aims at determining the circumstances to be faced by the organization or company in various aspects. Furthermore, the potential emergence and severity of losses are assessed (risk assessment).

The next stage is selecting and implementing risk management measures (response). The challenge in risk management is determining the right portfolio to form an integrated strategy. Such a strategy ensures the risks are appropriately dealt with through avoidance, reduction, sharing, transfer acceptance, and management plan creation. The next stage is implementing (implementation) all the methods planned to reduce or mitigate the effects of any existing risks. It is accompanied by evaluation and review by opening up the possibility of adjustments to current conditions.

According to Jerome Payne (2020: 2), the behavioral approach to managing and mitigating risk management was summarized by Kotter's Model. This approach involves 3 stages, including planning, enabling, and embedding. Business risk management mitigation in the Covid 19 pandemic requires companies to create new climate change habits acceptable and in line with all organizational levels and culture. Hence, when the necessary changes are initiated, all business organization members accept and regularly implement them with order, responsibility, and discipline.

When business risk management mitigation is planned correctly, new behavioral changes should be communicated. Also, actions to implement the behavioral changes should be initiated (enabling). The next step is the momentum where changes producing a new culture are integrated into business organizations' habits and structures (embedding).

\section{Research Methods}

This research uses a qualitative approach with a literature study. It focuses on business and management mitigation risk factors in Covid 19 pandemic, as well as their impact on its transmission. 


\section{Discussion}

As previously mentioned, various perspectives on business risk management due to the Covid 19 pandemic were conducted. They include examining the macro and micro risks from an economic perspective and their impact on consumer behavior. Moreover, there is a perspective on building risk management mitigation in SCM.

This research investigates the business risks in the Covid 19 pandemic. Moreover, it builds a strategy to mitigate or manage the Covid 19 transmission risk in the business environment. Consequently, this ensures the anticipation of the risk of imposing tighter social restrictions with significant business losses and the impact of risk management mitigation on the Covid 19 transmission.

\subsection{Business Risks in the Covid 19 Pandemic}

The business risk due to Covid 19 pandemic affects private businesses and the state as part of a public organization entity equally responsible for solving the problem. Undeniably, the strict social restrictions in dealing with the Covid 19 transmission significantly influence consumer behavior and purchasing power. Consequently, businesses experience difficulties due to a decrease in sales turnover caused by decreased consumer demand.

The World Bank issued a press release number NO: 2020/209 / EFI. It emphasized that the rapid and massive coronavirus pandemic shocks and measures to overcome it have caused a severe contraction of the global economy. According to World Bank forecasts, the global economy is to decline by $5.2 \%$ this year (World Bank, June 82020 ).

Everyone in the developed and developing countries affected by the Covid 19 transmission experiences difficulties in business due to risk. Eventually, these risks cannot be avoided, including those that seriously disrupt business continuity.

COVID-19 has generated significant uncertainty, fear, and extreme volatility in financial markets. It affects tourism, travel, hospitality, supply chains, consumption, production, operations, valuation, and security. Moreover, the Covid 19 disease causes financial stress, as well as affecting the prices of all products, including fossil fuels and renewable energy sources (Chia-Lin Chang, Michael McAleer, and Wing-Keung Wong, 2020).

After the conference of the G20 Finance Ministers and the Governor of Central Bank Director, the IMF issued a press release number 20/98. According to Kristalina Georgieva, the IMF Executive, there have been untold human losses from the Coronavirus pandemic. Therefore, all countries should work collaboratively to protect people and limit economic damage (IMF, March 23, 2020).

Countless businesses in many countries are closing due to bankruptcy and a lack of capital flexibility to face uncertainty during a pandemic. Furthermore, countless countries have experienced economic recessions despite the correction of negative growth and a reduction in trade between nations (Ocampo, 2020).

According to Mary Loxton, Robert Truskett, Brigitte Scarf, Laura Sindone, George Baldry, and Yinong Zhao (2020), amid the COVID-19 crisis, consumers behave in in ways similar to during historic shock events. Such historical crises and shock events include the SARS outbreak in 2002-04, Christchurch earthquake in 2011, and Hurricane Irma in 2017. Similarly, the COVID-19 significantly influences the changes in consumer behavior, affecting global economic conditions. This results in significant economic downturns, company, and industry failures, as well as increased unemployment. 
Countries are experiencing a decline in the food supply, accompanied by currency devaluation. In line with this, Erokhin and Tianming Gao (2020) examined the impact of COVID-19 from 45 Developing Countries. The results showed a risk of food security due to a health crisis, especially related to economic access to adequate food supplies. Moreover, the risk of food availability security due to restrictions on trade and currency depreciation is more pronounced in high-income developing countries.

\subsection{Risk Management Mitigation}

The easing of social restrictions in business due to the dangers of Covid 19 transmission should be interpreted to include possible risks. This includes the risk of increased Covid 19 transmission as part of business risk management calculations. The Australian Commission on Safety and Quality of Health Care (2020) emphasizes updating and incorporating organizational risk management plans with responses to COVID-19.

This means that managing the risk of Covid 19 transmission in a business environment should be an inherent responsibility. It should be implemented responsibly, carefully, sensitively, and strictly. Moreover, it has to be conducted with discipline and zero tolerance for any negligence.

The social restrictions were eased in various countries, including Indonesia's big cities, significantly affected by the Covid 19 transmission. However, this was followed by increased transmission in office and business environments, such as restaurants.

Various domestic and global facts inductively justify that business is ready with a risk management mitigation plan for the Covid 19 transmission. This has an impact on the risk of uncertainty for business sustainability.

May McMaster, Charlie Nettleton, Christeen Tom, Holland $\mathrm{Xu}$, Cheng Cao, and Ping Qiao (2020) provided lessons on building a business risk management mitigation during a pandemic. However, these steps were not related to mitigating the risk of Covid 19 transmission at work or in a business environment.

It is essential to learn the flexibility and adjustment steps in anticipating the adverse pandemic effects on comprehensive supply chain interests. The company implements a risk buffering strategy, helping suppliers from potential bankruptcy, adhering to health protocols, having flexibility in managing inventories, and utilizing online technology to support the business.

All business actors must prepare and comprehensively plan various aspects in the workplace, office, or business environment to anticipate and reduce the risk of Covid 19 transmission. This involves following health protocols, as well as discerning all possible transmissions from various direct and indirect workplace interactions.

The arrangement of ventilation, seating, and the number of people is generally known. However, the knowledge should cover the public facilities used interchangeably or simultaneously by many people. Additionally, people should ensure these places are not a source of the Covid 19 transmission. Toilets and bathrooms are necessary for everyone living long enough in a workplace, business environment, or place to eat. As a result, they are potentially an effective medium for Covid 19 transmission without strict and vigilant management.

The Government of Canada (2020) created risk mitigation instruments in workplaces and businesses operating during a pandemic. These instruments track workers' interactions with suspected Covid 19, identify vulnerable groups, and personal adherence to health protocols. Furthermore, they prevent sick people from working, promote, and facilitate health protocols, as well as mitigate the risk of public facilities becoming a means of Covid 19 spreading. 
One mitigation instrument of the Canadian government asks whether employees frequently come into contact with high-intensity touch surfaces, such as by other people. Another question is whether the customer frequently comes into contact with highintensity touch surfaces. A higher contact frequency with high touch-intensity surfaces, such as door handles, service counters, card payment machines, implies a greater risk.

New habitual culture is a behavioral change based on Kotter's Model's approach by Jerome Payne (2020: 2), including planning, enabling, and embedding. Moreover, according to Jasmin Harvey's approach (2005), the behavioral approach could be combined with evaluation and review. Hence, it is applicable in building business risk management mitigation to control the Covid 19 transmission in the workplace or a business environment.

The Australian Commission on Safety and Quality of Health Care (2020) technically described health care organizations. This includes Aboriginal communities and health services, and residential elderly care facilities. Additionally, the commission states the need to mitigate or manage the risk of COVID-19 transmission with the following guidelines:

1. Updating and incorporating the risk management plan across the organization with the response to COVID-19;

2. Regularly assessing the risk for the spread of COVID-19 in owned facilities;

3. Complying with precautionary and transmission-based standards according to government guidelines to prevent and control health infection;

4. Using protocols to select workers, patients, and visitors at risk of COVID-19 and other acute infectious infections;

5. Fulfilling physical distancing requirements during examination and care administration unless they are unavoidable. Standard and infection-based precautions in these circumstances should be appropriately exercised;

6. Promoting adherence to cough etiquette and respiratory hygiene by the workforce, patients, and visitors at all times.

Workforce protection is carried out using a management approach method. This method is very helpful for company leaders to exercise control over the implementation of occupational safety and health in the company and through the occupational safety and health management system, company leaders can find out the extent to which occupational safety and health programs are implemented in their companies (Marbun, 2020).

\subsection{The Impact of Risk Management Mitigation on the Covid 19 Transmission}

There needs to be a proper theoretical, conceptual, and empirical risk management mitigation of Covid 19 transmission. Consequently, this enhances the control of transmission in office and business place clusters. This is because various mitigation measures are theoretically and conceptually aimed at reducing the spread of Covid 19. For instance, various mitigation strategies have been taken to slow the rapid spread of COVID19. These include total or partial lockdowns, travel bans, restrictions on mass gatherings, home quarantine in the community, social distancing and personal protective measures, as well as other non-pharmaceutical interventions.

Empirically, an important lesson is the controlled Covid 19 transmission in Jakarta's traditional markets. Strict sanctions were imposed for traditional markets and temporary closure of Covid 19 transmission centers. Hence, all business actors or traders in the market feel they are collectively responsible for strict adherence to health protocols. Consequently, traditional markets in Jakarta are no longer a cluster for the spread of Covid 19. 
The risk management mitigation of Covid 19 transmission in offices or businesses is generally more specific. However, vigilant, careful, and disciplined risk management mitigation in the workplace results in positive, logical, and practical consequences on controlling the Covid 19 transmission. Therefore, this minimizes the risk of business continuity and uncertainty, as well as enhancing its consistency.

\section{Conclusion} results:

The following conclusions and suggestions were obtained based on the discussion

\subsection{Conclusions}

a. Business risks due to the Covid 19 pandemic affect private businesses and the state as part of a public organization entity equally obligated with solving the same problem;

b. The Covid-19 pandemic significantly influences the changes in consumer behavior and global economic conditions. This results in a significant economic downturn, corporate and industrial failures, and increased unemployment;

c. Food security risks are caused by a health crisis, especially economic access to adequate food supplies. Due to trade restrictions and currency depreciation, the food security risk is more common in high-income developing countries.

d. Various domestic and global facts inductively justify that no business is ready with adequate risk management planning for Covid 19 transmission. Hence, this influences the risk of uncertainty over business continuity;

e. A new habitual culture is a behavior change. The behavioral approach to Kotter's Model by Jerome Payne (2020: 2), which involves planning, enabling, and embedding, could be integrated with evaluation and review based on Jasmin Harvey's approach (2005). Hence, it becomes applicable in building risk management mitigation to control the Covid 19 transmission in the workplace or a business environment;

f. The risk management of Covid 19 transmission should be mitigated theoretically, conceptually, and empirically done well. Consequently, it positively influences the control of Covid 19 transmission in office clusters and business premises.

\subsection{Suggestions}

a. At the government policy level, the mitigation of Covid 19 transmission risk should be strategized more comprehensively. They should not rely on health protocols as part of prevention efforts. However, they must also implement policies to increase people's immune system;

b. Policies to restrict food trade between countries with the potential to impact scarcity could be anticipated by mitigating risks. These include promoting the optimization of unused land and cultivating community yards;

c. Management of the risk of Covid 19 transmission in a business environment should be an inherent responsibility. It should be conducted in an appropriate, sensitive, strict, and disciplined manner with zero tolerance to negligence;

d. Future research should focus more on developing ways and business strategies to mitigate risk management based on its needs. 


\section{References}

Australian Commission on Safety and Quality of Health Care, 2020, GUIDANCE for health service organizations: COVID-19: Infection prevention and control risk management, https://www.safetyandquality.gov.au

Canada Government, 2020, Risk mitigation tool for workplaces/businesses operating during the COVID-19 pandemic, https://www.canada.ca/en/publichealth/services/diseases/2019-novel-coronavirus-infection/guidance-documents/riskinformed-decision-making-workplaces-businesses-covid-19-pandemic.html

Chia-Lin Chang, Michael McAleer, dan Wing-Keung Wong, 2020, Risk and Financial Management of COVID-19 in Business, Economics, and Finance, Received: May 18, 2020; Accepted: May 19, 2020; Published: May 20, 2020, Journal of Risk Financial Management. 2020, 13, 102; DOI:10.3390/jrfm13050102,

Dorfman. 1998. Introduction to Risk Management And Insurance. Edisi Keenam. Upper Saddle River, NJ: Prentice Hall

Erokhin and Tianming Gao, 2020, Impacts of COVID-19 on Trade and EconomicAspects of Food Security: Evidence from 45 Developing Countries, International Journal of Environmental Research and Public Health, Received: July 15, 2020; Accepted: August 2, 2020; Published: August 10, 2020, Int. J. Environ. Res. Public Health 2020, 17, 5775; DOI:10.3390/ijerph17165775, www.mdpi.com/journal/ijerph

Harvey, Jasmin, 2005, FICC Markets Standards Board: Statement of Good Practice for FICC Market Participants: Conduct Training, https://fmsb.com/wpcontent/uploads/2017/01/16-12-08-SoGP-Conduct-Training_FINAL.pdf

International Monetary Fund (IMF), 2020, The Great Lockdown: Worst Economic Downturn Since the Great Depression, IMF Communications Department, Media Relations, Press Officer: Alistair https://www.imf.org/en/News/Articles/2020/03/23/pr2098-imf-managing-directorstatement-following-a-g20-ministerial-call-on-the-coronavirus-emergency

Jerome Payne, 2020, Managers, and Operational Risk Management in theCovid-19 'New Normal,' ttps://www.fitchlearning.com/

Kasidi, 2010, Manajemen Risiko. Bogor: Ghalia Indonesia.

Kertonegoro, s., 1996, Manajemen Risiko dan Asuransi. Jakarta: Toko Gunung Agung. Kerzner, Harold, 2004, Project management. New York: John Wiley \& Sons, Inc.

Marbun, J. (2020). Juridical Analysis of the Occupational Safety and Health Management System in the Company. Budapest International Research and Critics InstituteJournal (BIRCI-Journal). P. 895-901.

Mary Loxton, Robert Truskett, Brigitte Scarf, Laura Sindone, George Baldry dan Yinong Zhao, 2020, Consumer Behaviour during Crises: Preliminary Research on How Coronavirus Has Manifested Consumer Panic Buying, Herd Mentality, Changing Discretionary Spending and the Role of the Media in Influencing Behaviour, Received: June 24, 2020; Accepted: July 19, 2020; Published: July 30, 2020, Journal Risk Financial Manag. 2020, 13, 166; DOI: 10.3390/jrfm13080166

May McMaster, Charlie Nettleton, Christeen Tom, Belanda Xu, Cheng Cao dan Ping Qiao, 2020, Risk Management: Rethinking Fashion Supply Chain Management for Multinational Corporations in Light of the COVID-19 Outbreak, Received: June 24, 2020; Accepted: July 27, 2020; Published: August 4, 2020, Journal Risk Financial Manag. 2020, 13, 173; DOI: 10.3390/jrfm13080173.

Ocampo, José Antonio, 2020, Uncertainties surrounding the global economy and their implications for the global development agenda, Recover Better: Economic and 
Social Challenges and Opportunities, A Compilation of the United Nations Highlevel Advisory Board on Economic and Social Affairs, Departement of Economic and Social Affairs, United Nations, https://www.un.org/development/desa/en/wpcontent/uploads/2020/07/Recover_Better_0722-1.pdf.

Siagian, Faira dan Sekarsari, Jane. 2001, Penerapan Model Manajemen Risiko pada Proyek Konstruksi Joint Venture di Indonesia Suatu Studi Kasus, Universitas Trisakti, Jakarta.

World Bank, 2020, COVID-19 to Plunge Global Economy into Worst Recession since World War II, World Bank Press Release, 8 Juni 2020, https://www.worldbank.org/en/news/press-release/2020/06/08/covid-19-to-plungeglobal-economy-into-worst-recession-since-world-war-ii 